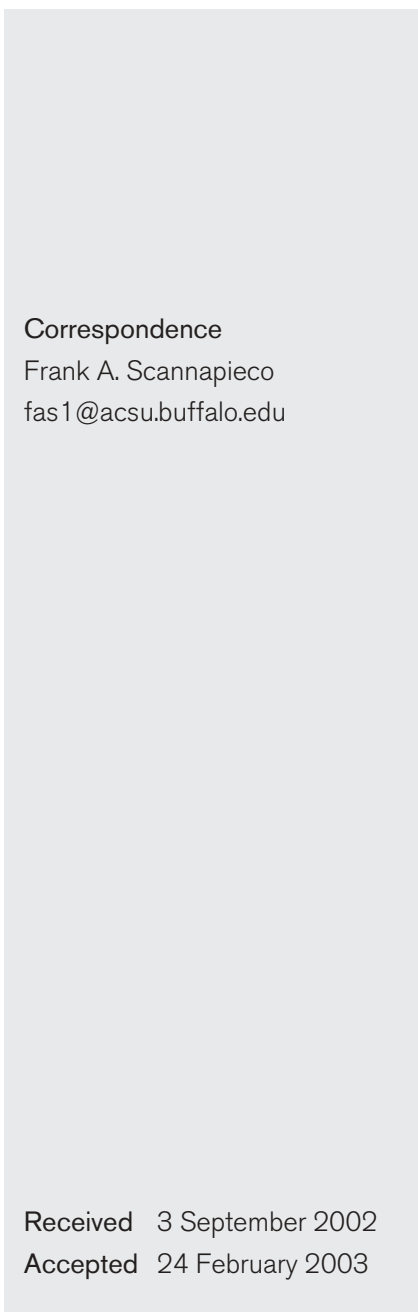

\title{
Molecular analysis of bacterial flora associated with chronically inflamed maxillary sinuses
}

\author{
Susanna Paju, ${ }^{1}$ Joel M. Bernstein, ${ }^{2}$ Elaine M. Haase $^{1}$ \\ and Frank A. Scannapieco ${ }^{1}$
}

Department of Oral Biology, School of Dental Medicine ${ }^{1}$ and Department of Otolaryngology, School of Medicine and Biomedical Sciences ${ }^{2}$, State University of New York at Buffalo, Buffalo, NY 14214, USA

\begin{abstract}
Chronic maxillary sinusitis is a chronic inflammatory condition in which the role of microbial infection remains undefined. Bacteria have been isolated from chronically inflamed sinuses; however, their role in the chronicity of inflammation is unknown. The objective of this study was to determine whether bacteria are present in clinical samples from chronic maxillary sinusitis and to assess the diversity of the flora present. Washes and/or tissue samples from endoscopic sinus surgery on 11 patients with chronic maxillary sinusitis were subjected to PCR amplification of bacterial 16S rDNA using three universal primer pairs, followed by cloning and sequencing. The samples were also assessed for the presence of bacteria and fungi by conventional culture methods. Viable bacteria and/or bacterial 16S rDNA were detected from maxillary sinus samples of five of the 11 patients examined ( $45 \%)$. Three sinus samples were positive by both PCR and culture methods, one was positive only by PCR, and one only by culture. Thirteen bacterial species were identified: Abiotrophia defectiva, Enterococcus avium, Eubacterium sp., Granulicatella elegans, Neisseria sp., Prevotella sp., Pseudomonas aeruginosa, Serratia marcescens, Staphylococcus aureus, Stenotrophomonas maltophilia, Streptococcus gordonii, Streptococcus mitis/Streptococcus oralis and Streptococcus sp. Fungi were not detected. In one patient Streptococcus mitis/Streptococcus oralis, and in another patient Pseudomonas aeruginosa, were detected from both the sinus and the oral cavity using species-specific PCR primers. These results suggest that both aerobic and anaerobic bacteria can be detected in nearly half of chronic maxillary sinusitis cases.
\end{abstract}

\section{INTRODUCTION}

The maxillary sinus is a unique anatomical structure that varies in size and form, warms and moistens breathed air, resonates the voice and lightens the skull. The secretions of the sinus are cleared by cilia. Maxillary sinuses are considered to be sterile in health, but may sometimes be colonized by bacteria in the absence of clinical symptoms (Jiang et al., 1999). The diagnostic criteria for acute maxillary sinusitis are well-established, but the definition of chronic maxillary sinusitis is controversial with respect to the importance of bacteria in the initiation and progression of the disease. Aspirates from community-acquired acute rhinosinusitis usually harbour bacterial species such as Streptococcus pneumoniae, Haemophilus influenzae and Moraxella catarrhalis (Gwaltney, 1996). In contrast, microbiological cultures from chronically inflamed sinuses that fail to respond to antibiotic therapy are often found to be sterile or to harbour a limited number of bacterial species, such as coagulase-

The GenBank/EMBL/DDBJ accession numbers for the $16 \mathrm{~S}$ rDNA sequences reported in this study are AY307987-AY307998. negative staphylococci, Prevotella spp. or Fusobacterium nucleatum (Brook et al., 1997; Chan \& Hadley, 2001). Chronic sinusitis has thus been considered to be a chronic inflammatory condition rather than a microbial infection. The role of bacteria in the chronicity of inflammation is unknown. Further studies are therefore needed to define the microbiology of chronic sinusitis and to determine the proper use of antibiotic therapy, if necessary, in the management of this condition.

Reports of bacterial growth in chronic maxillary sinusitis range from $36 \%$ of mucosal specimens taken by translabial antroscopy (Jiang et al., 1998) to $92 \%$ of sinus aspirates (Brook et al., 1997). However, only a limited number of bacterial genera have been detected using conventional culture techniques (Wilson et al., 1997). Novel cultureindependent methods that involve PCR amplification of bacterial small-subunit rDNA followed by cloning and sequencing have recently been used to determine the diversity of bacterial flora within specific environments, such as deep-sea sediments (Kato et al., 1997) and hot springs (Hugenholtz et al., 1998). In humans, studies using these 
methods suggest that about $40 \%$ of clones in the oral cavity (Paster et al., 2001) and about $70 \%$ of clones in the gut and colon (Suau et al., 1999; Wilson \& Blitchington, 1996) do not correspond to known organisms, and are therefore novel (and probably non-cultivable) species. A previous study found PCR to be more efficient than standard culture for the detection of aerobic bacteria in chronic rhinosinusitis; such bacteria were detected in $62 \%$ of samples tested by PCR, compared to $50 \%$ using culture techniques (Keech et al., 2000). However, definitive studies that describe the total bacterial flora of the chronically inflamed maxillary sinus using molecular methods are not yet available.

Oral infections and inflammatory diseases such as periodontitis may influence systemic health by contributing to underlying mechanisms responsible for chronic coronary heart disease (Beck et al., 1999), pregnancy complications (Offenbacher et al., 1998), diabetes (Grossi \& Genco, 1998) and respiratory infections (Scannapieco, 1999). The oral cavity may also serve as a reservoir for infection of contiguous structures such as the sinuses or middle ear. Oral bacteria may ascend from the mouth through the middle meatus to the maxillary sinus, or through the Eustachian tube to the middle ear, causing infections. Dental conditions such as periodontitis or periapical granuloma have been associated with $40 \%$ of chronic maxillary sinusitis cases (Melen et al., 1986). Typically oral anaerobic bacteria such as Porphyromonas, Prevotella and Fusobacterium species can be detected by culture methods in infections of the middle ear (Brook et al., 2000), tonsils (Rajasuo et al., 1996) and sinuses (Le Moal et al., 1999). Aerobic species that normally reside in the oral cavity, such as viridans streptococci, have also been found in chronic sinusitis (Biel et al., 1998). Additionally, elevated serum levels of antibodies against F. nucleatum and Prevotella intermedia have been observed in patients with chronic maxillary sinusitis (Brook \& Yocum, 1999).

The objective of this study was to determine whether bacteria were present in clinical samples from chronic maxillary sinusitis. We also attempted to determine if bacteria detected within the chronically inflamed maxillary sinus were simul- taneously present in the oral cavity of the same patient. Using culture-independent methods, we also aimed to detect novel as-yet-uncultivable bacterial species in the chronically inflamed maxillary sinus.

\section{METHODS}

Subjects. Eleven adult patients with a history of chronic maxillary sinusitis, who had been referred to an ear, nose and throat surgeon (J.M.B.) for endoscopic sinus surgery, were studied (Table 1). Each patient had at least $50 \%$ opacification of the sinus, as determined by lateral radiographical scans. There was no evidence of clinical disease of the gingiva or periodontal tissues, or of endodontically involved teeth, as the cause of the sinus condition. Some of the subjects had received standard courses of antibiotic treatment, but none of them had received antibiotics for at least 2 weeks prior to sample collection. This protocol was approved by the State University of New York at Buffalo Human Studies Institutional Review Board, and informed consent was obtained from each subject enrolled in the study.

Specimen collection. Washes and/or tissue samples from maxillary sinuses were obtained during standard surgical treatment as follows: after sterilization of the nasal vestibule and inferior meatus with ethanol, a sterile $18 \mathrm{G}$ trocar needle was introduced into the maxillary sinus. Tissue specimens were aspirated directly from the sinus, or the sinus was irrigated with sterile saline and the fluid was removed with a sterile $10 \mathrm{~cm}^{3}$ syringe attached to the trocar. Oral swabs from the buccal marginal gingiva in the maxillary premolar regions of both sides of the mouth were also collected at the time of surgery. A portion of each maxillary sinus sample was sent to a clinical laboratory for microbiological culture, and the remaining samples were stored at $-70{ }^{\circ} \mathrm{C}$ until they were processed for PCR analysis.

Microbiological culture. Samples were transported to the clinical laboratory in brain heart infusion solution for routine cultivation of bacteria and fungi. Samples were cultured in thioglycollate broth and on blood, chocolate, MacConkey, Columbia CNA, Sabouraud and Mycosel (Becton Dickinson) agars. All media were maintained aerobically at $37^{\circ} \mathrm{C}$ in $5 \% \mathrm{CO}_{2}$. Any growth in thioglycollate broth was subcultured to blood agar and incubated both aerobically and anaerobically. The lower limit of culture detection was approximately 100 c.f.u. (ml sample $)^{-1}$.

Specimen digestion and DNA extraction. Tissue samples and oral swabs were suspended in sterile $\mathrm{dH}_{2} \mathrm{O}$. Maxillary washes (at least $4 \mathrm{ml}$ )

Table 1. Study subjects with persistent chronic maxillary sinusitis

\begin{tabular}{|lcclclc|}
\hline Patient & Sex & Age & Co-morbidity & $\begin{array}{c}\text { Antibiotic } \\
\text { treatment }\end{array}$ & $\begin{array}{c}\text { Antibiotics } \\
\text { Time without antibiotics } \\
\text { prior to surgery }\end{array}$ \\
\hline 1 & M & 58 & None & Yes & Amoxicillin/clavulanate, clindamycin & 2 months \\
2 & M & 63 & None & No & - & - \\
3 & F & 36 & None & Yes & Amoxicillin/clavulanate, cefprozil, levofloxacin & 1 year \\
4 & F & 32 & Sarcoidosis & Yes & Levofloxacin & 2 months \\
5 & F & 53 & None & No & - & - \\
6 & F & 52 & None & No & - & - \\
7 & M & 45 & None & No & - & - \\
8 & M & 25 & Cystic fibrosis & Yes & Amoxicillin/clavulanate & 4 months \\
9 & M & 26 & None & No & - & - \\
10 & F & 49 & Asthma & Yes & Levofloxacin & 7 months \\
11 & F & 40 & None & Yes & Moxifloxacin & 2 weeks \\
\hline
\end{tabular}


were centrifuged at $10000 \mathrm{~g}$ for $30 \mathrm{~min}$ and the resulting pellet was suspended in sterile $\mathrm{dH}_{2} \mathrm{O}$. An equal volume of lysis buffer containing $400 \mu \mathrm{g}$ proteinase $\mathrm{K} \mathrm{ml}^{-1}$, $2 \%$ SDS (w/v), $100 \mathrm{mM}$ Tris/HCl (pH 8.5) and 2 mM EDTA (Kroes et al., 1999) was added to all samples, which were then incubated at $55{ }^{\circ} \mathrm{C}$ overnight. DNA was extracted by phenol/ chloroform extraction and ethanol precipitation. Isolation of DNA from each sample was confirmed by agarose gel electrophoresis and ethidium bromide staining; the DNA was stored at $-70{ }^{\circ} \mathrm{C}$ until use.

PCR amplification of 165 rDNA. PCR was performed in a reaction volume of $50 \mu \mathrm{l}$, consisting of $0.2 \mathrm{mM}$ each dNTP (Invitrogen), $0 \cdot 4 \mu \mathrm{M}$ each primer, $5 \mu \mathrm{l} 10 \times$ PCR buffer (Promega), $1.5 \mathrm{mM} \mathrm{MgCl}_{2}$ and $1 \mathrm{U}$ Taq DNA polymerase (Promega). The three universal primer pairs used to amplify bacterial $16 \mathrm{~S} \mathrm{rDNA}$ were $27 \mathrm{f}$ ( $5^{\prime}$-AGAGTTTGATCCTGGCT CAG-3') and 1492r (5'-GGTTACCTTGTTACGACTT-3') (Lane et al., 1985), 63f (5'-CAGGCCTAACACATGCAAGTC-3') and 1387r [5'GGGCGG(A/T)GTGTACAAGGC-3'] (Marchesi et al., 1998), and SDBact0338aA18 (Bact-338) (5'-ACTCCTACGGGAGGCAGC-3') and SDBact1525aS17 (Bact-1525) (5'-AAGGAGGTGATCCAGCC-3') (Kroes et al., 1999). Negative controls, consisting of a reagent control (sterile water used as a template in the PCR reagent mixture) and a control for sample preparation (sterile water prepared in the same way as the samples), were included in each set of PCR amplifications. Chromosomal DNA from Escherichia coli was used as a positive control. PCR amplification was performed with 30 cycles as follows: denaturation at $94{ }^{\circ} \mathrm{C}$ for $1 \mathrm{~min}$, annealing at $55^{\circ} \mathrm{C}$ for $1 \mathrm{~min}$ and extension at $72{ }^{\circ} \mathrm{C}$ for $2 \mathrm{~min}$. Amplification products were separated by $1.0 \%$ agarose gel electrophoresis and visualized under UV light after staining with ethidium bromide. To exclude false negative results caused by inhibitors in the sample, several dilutions of the original sample were used as a template, followed by a second PCR using the amplified product as a template. Each negative result was confirmed at least four times. In the literature, the lower detection limit for PCR has been estimated to be from a few bacterial cells to more than 100 c.f.u. per PCR (Ahmet et al., 1999; Gram et al., 1996; Rantakokko-Jalava et al., 2000); this variation is most likely to depend on the type of clinical sample studied (fluid versus tissue, or mixed versus single bacterial species).

Cloning of amplified 16S rDNA. The $16 \mathrm{~S}$ rDNA products were purified using the Wizard PCR Preps DNA purification system (Promega). The purified amplicon was ligated into the vector pGEM$\mathrm{T}$ (Promega) and transformed into E. coli $\mathrm{DH} 5 \alpha$ competent cells (Invitrogen), according to the manufacturers' instructions. From each sample, 100-200 ampicillin-resistant transformants, identified as white colonies on LB agar containing IPTG (Invitrogen) and X-Gal (Fisher Scientific) after overnight incubation at $37^{\circ} \mathrm{C}$, were selected for further study. Cells from representative colonies were suspended in $50 \mu \mathrm{ldH}_{2} \mathrm{O}$, boiled, and the supernatant was used as a template in PCR with primers M13 forward (5'-GTAAAACGACGGCCAGT-3') and M13 reverse (5' GGAAACAGCTATGACCATG-3') to determine if the clone had a correctly sized insert. PCR products with inserts of appropriate size were further used as templates in a second PCR with the bacterial-specific 16S rDNA primer pair used in the original PCR amplification. To reduce the overrepresentation of any species when selecting clones for sequencing, PCR products were digested with the restriction endonucleases HaeIII, BamHI and Sau3AI for 1-2 h, enzymes were inactivated by heating, and RFLP profiles were run on $1 \%$ agarose gel (Kroes et al., 1999; Dymock et al., 1996). At least 20 positive inserts from each patient were analysed by RFLP, and additional clones were examined if more than one RFLP profile was distinguished. Up to five representative clones of each unique restriction pattern were selected for sequencing.

Sequencing and phylogenetic analysis. Plasmids for sequencing were prepared by using the Wizard Plus SV Minipreps DNA purification system (Promega). DNA sequencing was performed using primer T7, complementary to the vector pGEM-T, by the Biopolymer Facility at the
Roswell Park Cancer Institute, Buffalo, NY, USA. Sequences of inserts were compared to the 16S rRNA gene sequences in GenBank using BLAST software. DNA sequences sharing $\geqslant 98 \%$ identity with known sequences were assigned to that phylotype.

Detection of bacterial species identified from maxillary sinuses in oral samples from the same patient. For each patient, an attempt was made to detect the species obtained from the sinus within the oral sample obtained at the time of sinus surgery. Primers specific to Streptococcus oralis/Streptococcus mitis (5'-GTCGAAGGTGATGATAT GAC-3' and 5'-CTGCATTCTGACGCATGACAG-3') (Garnier et al., 1997), Streptococcus gordonii (5'-TGATGAAGCTACTGATGC-3' and 5'-TAACAACGCTGCAGAAGACAA-3') (Brown et al., 1999), Staphylococcus aureus (5'-GTTATTAGGGAAGAACATATGTG-3' and 5'-CCACCTTCCTCCGGTTTGTCACC-3') (Jaffe et al., 2000), Pseudomonas aeruginosa (5'-AGGGCAGTAAGTTAATACCTTGCTG-3' and 5'-CCACCTCTACCGTACTCTAGCTCAG-3') (Wilson et al., 1999) and Serratia marcescens (5'-GGGAGCTTGCTCACTGGGTG-3' ${ }^{\prime}$ and 5'-GCGAGTAACGTCAGTTGATGAGCGTATTA-3') (Wilson et al., 1999) were used in PCR amplifications as described in this study and the original publications. Respective sinus clones were used as positive controls in PCR amplifications.

\section{RESULTS}

\section{Detection and identification of bacteria and bacterial 165 rDNA in maxillary sinuses}

Bacteria and/or bacterial $16 \mathrm{~S}$ rDNA were detected in maxillary sinus samples from five of the 11 patients examined ( 45 $\%$; Table 2). Positive PCR amplifications were obtained with $1-3$ of the bacterial species-specific primer pairs used. Three sinus samples (patients 3, 4 and 6) were positive by both PCR and culture methods (Table 2). One sample (patient 7) was positive only by PCR, and one (patient 11) was positive only by culture (Table 2). Table 3 shows the genera identified by PCR detection and sequencing of bacterial 16 S rDNA, as well

Table 2. Detection of bacteria and/or bacterial rDNA in maxillary sinuses of 11 patients with chronic maxillary sinusitis by PCR using three primer pairs and culture

+ , PCR product of predicted size or positive culture result; -, no PCR product or negative culture result.

\begin{tabular}{|c|c|c|c|c|}
\hline \multirow[t]{2}{*}{ Patient } & \multicolumn{3}{|c|}{ PCR primer pair } & \multirow[t]{2}{*}{ Culture } \\
\hline & $27 f, 1492 r$ & $63 \mathrm{f}, 1387 \mathrm{r}$ & Bact-338, Bact-1525 & \\
\hline 1 & - & - & - & - \\
\hline 2 & - & - & - & - \\
\hline 3 & - & - & + & + \\
\hline 4 & + & + & + & + \\
\hline 5 & - & - & - & - \\
\hline 6 & + & - & - & + \\
\hline 7 & + & + & + & - \\
\hline 8 & - & - & - & - \\
\hline 9 & - & - & - & - \\
\hline 10 & - & - & - & - \\
\hline 11 & - & - & - & + \\
\hline
\end{tabular}


as by bacterial culture from maxillary sinuses. In three cases (patients 6,7 and 11) only one bacterial species was detected, in one case (patient 4 ) three species were detected, and in one case (patient 3 ) nine different RFLP patterns were identified among the clones by PCR amplification and cloning, with the majority of the clones identified as Streptococcus spp. In patient 3, culture results indicated the presence of anaerobic Gram-positive bacilli, which correlated with PCR results that indicated the presence of Eubacterium sp. (Table 3). In patient 4, Pseudomonas aeruginosa was detected using both methods, and two additional species were detected by PCR (Table 3). The only species that was not detected by universal PCR was Staphylococcus aureus; all three cases that were culture-positive for Staphylococcus aureus were PCR-negative for this species. One of the bacteria-positive sinus samples (patient 6) gave so weak an amplification product after both the first and second PCRs using the universal primer pair (27f and 1492r) that it could not be processed further for cloning. As that particular maxillary sinus bacterial isolate was Staphylococcus aureus, the Staphylococcus $16 \mathrm{~S}$ rDNA primers (Jaffe et al., 2000) were used in PCR amplification of the maxillary sample. It was found to be positive for Staphylococcus rDNA. Sinus samples of two other patients (4 and 11) that were culture-positive but PCRnegative for Staphylococcus aureus were also amplified with Staphylococcus $16 \mathrm{~S}$ rDNA primers, but were found to be negative. Fungi were not isolated from the maxillary sinus samples, and were not tested for by molecular methods.

\section{Possible novel species}

The majority of the bacterial sequences identified in this study demonstrated $\geqslant 98 \%$ identity with previously known bacterial species. No previously unrecognized species were recovered, but one clone from patient 4 demonstrated $94 \%$ sequence identity with a Prevotella sp. oral clone, and one clone from patient 3 demonstrated $96 \%$ sequence identity with an Enterococcus avium strain when $>1000$ bp were compared. As $<97 \%$ similarity is considered to differentiate species within genera (Stackebrandt \& Goebel, 1994) and $<90 \%$ similarity to represent a species from an unknown genus, these clones may represent novel species related to Prevotella or Enterococcus.

\section{Relationship between bacteria detected in the maxillary sinus and the oral cavity by PCR}

In patient 3 , nine different bacterial clones were identified from the maxillary sinus; the majority of these clones were typically oral species such as Streptococcus sp., nutritionally variant streptococci, Eubacterium sp. or Neisseria sp. In the same patient, an attempt was made to detect the same species in the oral cavity. Indeed, a positive result was obtained with Streptococcus mitis/Streptococcus oralis primers, but a negative result was obtained with Streptococcus gordonii primers. In patient 4 , a Prevotella clone with a possible oral origin was detected in the maxillary sinus. Also, in patient 4 , attempts to find the same species by molecular methods from the oral cavity gave positive results with Pseudomonas aeruginosa 
primers and negative results with Staphylococcus aureus and Serratia marcescens primers. In patients 6 and 11, Staphylococcus aureus, which was present in the maxillary sample, was not detected in the oral sample by molecular methods. For the other species identified in the maxillary sinuses, specific primers were not available or the primers designed as described in previous studies did not work in our laboratory with the matched species DNA.

\section{DISCUSSION}

In the present study, maxillary sinus tissue samples and/or washes obtained from adult patients with a history of chronic maxillary sinusitis were examined for the presence of bacteria. In addition to bacterial culture, PCR amplification of bacterial $16 \mathrm{~S}$ rDNA followed by cloning and sequencing was employed to detect and identify non-cultivable bacterial species within the sinus. To determine whether the oral cavity may serve as a source of bacterial colonization of the maxillary sinus, an attempt was also made to correlate the species identified in the maxillary sinus with the dental plaque from the same patients.

We detected bacteria and/or bacterial 16S rDNA in five of 11 patients $(45 \%)$. Our results corroborate those of some previous studies, where bacteria have been detected in mucosal specimens from approximately $50 \%$ of chronic maxillary sinusitis cases (Jiang et al., 1998; Hwang et al., 1999). However, other studies have reported that up to $92 \%$ of chronic sinusitis samples contain bacteria (Brook et al., 1997). The type of specimen and the methods of detection may contribute to the different results observed. Our results are based upon analysis of mucosal tissues or maxillary sinus washes, because no exudates were obtained from these patients. The results must also be interpreted with caution, as the present study was limited to 11 subjects. Studies of larger populations using culture-independent methods are necessary.

Of the three primer pairs used to amplify bacterial DNA in our study, primers $27 \mathrm{f}$ and $1492 \mathrm{r}$ are broadly conserved and have previously been widely used to detect bacteria in human biopsies and body fluids (Dymock et al., 1996; RantakokkoJalava et al., 2000). To enhance detection of some specific oral species such as Prevotella, two additional bacteria-specific primer pairs that were designed to detect oral species were used (Kroes et al., 1999; Marchesi \& Weightman, 2000). It is acknowledged that the absence of bacterial DNA in chronic maxillary sinusitis samples may simply be due to the fact that the number of bacteria in the sample was below the detection limit of the PCR method used.

Three maxillary sinus samples were positive by both PCR and culture methods. One sample was positive only by PCR, and one was positive only by culture. PCR has previously been found to be more sensitive than standard culture methods when mucosal specimens from chronic sinusitis were analysed for the detection of aerobic bacteria (Keech et al., 2000). However, in three cases where Staphylococcus aureus was detected by culture, it was PCR-negative or faintly positive, and therefore was not suitable for further analysis using universal PCR primers. Whilst every effort was made to collect sterile specimens, some of these culture-positive results could be the result of contamination of the sample during collection or processing. This may be particularly true in the case of patient 11, who received moxifloxacin, a fluoroquinolone that is effective against Staphylococcus aureus, 2 weeks before sample collection. This sample was PCR-negative but culture-positive for Staphylococcus aureus. Alternatively, the Staphylococcus-specific primers used here may not bind to the strains found in this study.

The species identified in the present study are not commonly associated with acute bacterial rhinosinusitis by culture methods (Gwaltney, 1996). The bacteria detected in maxillary sinuses in this study included several typically oral species, suggesting that the oral flora may be a source for bacterial colonization of the chronically inflamed maxillary sinus. Of these species, viridans streptococci have previously been identified in chronic maxillary sinusitis by culture methods (Biel et al., 1998), and elevated antibody levels to Prevotella intermedia have been observed in patients with chronic maxillary sinusitis (Brook \& Yocum, 1999). However, the presence of specific antibodies against an organism does not necessarily define it as a pathogen. Interestingly, Abiotrophia defectiva and Granulicatella elegans, previously classified as nutritionally variant streptococci and members of the normal flora of the oral cavity, throat, urogenital and intestinal tracts, were identified by molecular methods from the same maxillary sinus. These species are rarely cultured from clinical samples because of their fastidious nature, which may have contributed to the fact that they were detected and identified here only by molecular methods. Recent results from a multicentre study corroborate our findings by showing that Granulicatella species are associated with chronic maxillary sinusitis and may contribute to antibiotic treatment failure (Finegold et al., 2002).

Possible contiguous spread of bacterial flora from the oral cavity to the maxillary sinus was investigated by attempting to find the species detected in the sinus also in the oral cavity, using published species-specific primers. There were no primers available for some species, or the primers that were available did not work in our laboratory as described in the original publications, so our efforts were limited to about half of the species detected in the sinus. Two of five bacterial species found in the maxillary sinus were also found in the oral cavity by PCR using species-specific primers. The same Streptococcus mitis and/or Streptococcus oralis clone(s) were found in the oral cavity and the maxillary sinus in one patient. In another patient, Pseudomonas aeruginosa, identified in the maxillary sinus, was also found in the oral cavity. Previous studies suggest that oral colonization by potential respiratory pathogens may occur, and that dental plaque may serve as a reservoir for these organisms (Scannapieco et al., 1992). Unexpectedly, Streptococcus gordonii, a common colonizer of the oral cavity, was not found in the mouth of the patient who carried it in the maxillary sinus. Also, 
Staphylococcus aureus and Serratia marcescens were not detected in the oral samples. However, this does not rule out the possibility that these species may have been present in very low numbers in our samples and thus below the detection limit for the method.

As PCR does not distinguish viable from dead bacteria, we cannot say that the present cases of chronic maxillary sinusitis were definitely caused by the bacterial species isolated. It is possible that there were only dead bacteria or released DNA left in the sinuses from a past infection by these organisms. Bacterial DNA has been demonstrated to persist in human synovial fluid and tissue samples as long as 10-22 days after the initiation of antimicrobial treatment, whereas all samples became culture-negative by 2-3 days following the start of therapy (van der Heijden et al., 1999). In contrast, studies on chinchillas have shown that bacterial DNA can be found only for 1 day in the presence of middle ear effusion (Aul et al., 1998). The elimination of bacterial DNA may therefore depend on the body site and fluid. The role of bacteria in chronic sinusitis and related disorders has been questioned, and fungal pathogens have been proposed to be responsible for the inflammatory reaction and mucosal response in the sinus. However, in the present study, no fungi were detected in chronic maxillary sinusitis by culture and we did not attempt to detect fungi by molecular methods.

In conclusion, the present results suggest that both aerobic and anaerobic bacteria can be detected in nearly half of chronic maxillary sinusitis cases. The species identified in the present study are rarely associated with acute bacterial rhinosinusitis and include several oral species, suggesting that these are present in the inflamed maxillary sinus. The simultaneous detection of some bacterial species in the maxillary sinus and in the oral cavity shows that the direct connection between these two sites may allow oral bacteria to contribute to non-oral inflammatory conditions.

\section{ACKNOWLEDGEMENTS}

This study was supported in part by grants from the National Institutes of Health (DE 09838) and the Academy of Finland (no. 77271).

\section{REFERENCES}

Ahmet, Z., Stanier, P., Harvey, D. \& Holt, D. (1999). New PCR primers for the sensitive detection and specific identification of group $B$ $\beta$-hemolytic streptococci in cerebrospinal fluid. Mol Cell Probes 13, 349-357.

Aul, J. J., Anderson, K. W., Wadowsky, R. M., Doyle, W. J., Kingsley, L. A., Post, J. C. \& Ehrlich, G. D. (1998). Comparative evaluation of culture and PCR for the detection and determination of persistence of bacterial strains and DNAs in the Chinchilla laniger model of otitis media. Ann Otol Rhinol Laryngol 107, 508-513.

Beck, J. D., Pankow, J., Tyroler, H. A. \& Offenbacher, S. (1999). Dental infections and atherosclerosis. Am Heart J 138, S528-S533.

Biel, M. A., Brown, C. A., Levinson, R. M., Garvis, G. E., Paisner, H. M., Sigel, M. E. \& Tedford, T. M. (1998). Evaluation of the microbiology of chronic maxillary sinusitis. Ann Otol Rhinol Laryngol 107, 942-945.
Brook, I. \& Yocum, P. (1999). Immune response to Fusobacterium nucleatum and Prevotella intermedia in patients with chronic maxillary sinusitis. Ann Otol Rhinol Laryngol 108, 293-295.

Brook, I., Frazier, E. H. \& Foote, P. A. (1997). Microbiology of chronic maxillary sinusitis: comparison between specimens obtained by sinus endoscopy and by surgical drainage. J Med Microbiol 46, 430-432.

Brook, I., Yocum, P. \& Shah, K. (2000). Aerobic and anaerobic bacteriology of concurrent chronic otitis media with effusion and chronic sinusitis in children. Arch Otolaryngol Head Neck Surg 126, 174-176.

Brown, A. E., Rogers, J. D., Haase, E. M., Zelasko, P. M. \& Scannapieco, F. A. (1999). Prevalence of the amylase-binding protein A gene $(a b p A)$ in oral streptococci. J Clin Microbiol 37, 4081-4085.

Chan, J. \& Hadley, J. (2001). The microbiology of chronic rhinosinusitis: results of a community surveillance study. Ear Nose Throat J 80, 143-145.

Dymock, D., Weightman, A. J., Scully, C. \& Wade, W. G. (1996). Molecular analysis of microflora associated with dentoalveolar abscesses. J Clin Microbiol 34, 537-542.

Finegold, S. M., Flynn, M. J., Rose, F. V., Jousimies-Somer, H., Jakielaszek, C., McTeague, M., Wexler, H. M., Berkowitz, E. \& Wynne, B. (2002). Bacteriologic findings associated with chronic bacterial maxillary sinusitis in adults. Clin Infect Dis 35, 428-433.

Garnier, F., Gerbaud, G., Courvalin, P. \& Galimand, M. (1997). Identification of clinically relevant viridans group streptococci to the species level by PCR. J Clin Microbiol 35, 2337-2341.

Gram, T., Ahrens, P. \& Nielsen, J. P. (1996). Evaluation of a PCR for detection of Actinobacillus pleuropneumoniae in mixed bacterial cultures from tonsils. Vet Microbiol 51, 95-104.

Grossi, S. G. \& Genco, R. J. (1998). Periodontal disease and diabetes mellitus: a two-way relationship. Ann Periodontol 3, 51-61.

Gwaltney, J. M., Jr (1996). Acute community-acquired sinusitis. Clin Infect Dis 23, 1209-1223.

Hugenholtz, P., Pitulle, C., Hershberger, K. L. \& Pace, N. R. (1998). Novel division level bacterial diversity in a Yellowstone hot spring. J Bacteriol 180, 366-376.

Hwang, P. H., Montone, K. T., Gannon, F. H., Senior, B. A., Lanza, D. C. \& Kennedy, D. W. (1999). Applications of in situ hybridization techniques in the diagnosis of chronic sinusitis. Am J Rhinol 13, 335-338.

Jaffe, R. I., Lane, J. D., Albury, S. V. \& Niemeyer, D. M. (2000). Rapid extraction from and direct identification in clinical samples of methicillin-resistant staphylococci using the PCR. J Clin Microbiol 38, 34073412.

Jiang, R. S., Hsu, C. Y. \& Jang, J. W. (1998). Bacteriology of the maxillary and ethmoid sinuses in chronic sinusitis. J Laryngol Otol 112, 845-848.

Jiang, R. S., Liang, K. L., Jang, J. W. \& Hsu, C. Y. (1999). Bacteriology of endoscopically normal maxillary sinuses. J Laryngol Otol 113, 825-828.

Kato, C., Li, L., Tamaoka, J. \& Horikoshi, K. (1997). Molecular analyses of the sediment of the 11,000-m deep Mariana Trench. Extremophiles 1, $117-123$.

Keech, D. R., Ramadan, H. \& Mathers, P. (2000). Analysis of aerobic bacterial strains found in chronic rhinosinusitis using the polymerase chain reaction. Otolaryngol Head Neck Surg 123, 363-367.

Kroes, I., Lepp, P. W. \& Relman, D. A. (1999). Bacterial diversity within the human subgingival crevice. Proc Natl Acad Sci U S A 96, 1454714552 .

Lane, D. J., Pace, B., Olsen, G. J., Stahl, D. A., Sogin, M. L. \& Pace, N. R. (1985). Rapid determination of $16 \mathrm{~S}$ ribosomal RNA sequences for phylogenetic analyses. Proc Natl Acad Sci U S A 82, 6955-6959. 
Le Moal, G., Lemerre, D., Grollier, G., Desmont, C., Klossek, J. M. \& Robert, R. (1999). Nosocomial sinusitis with isolation of anaerobic bacteria in ICU patients. Intensive Care Med 25, 1066-1071.

Marchesi, J. R. \& Weightman, A. J. (2000). Modified primers facilitate rapid screening of $16 \mathrm{~S}$ rRNA gene libraries. Biotechniques 29, 48-50.

Marchesi, J. R., Sato, T., Weightman, A. J., Martin, T. A., Fry, J. C., Hiom, S. J., Dymock, D. \& Wade, W. G. (1998). Design and evaluation of useful bacterium-specific PCR primers that amplify genes coding for bacterial 16S rRNA. Appl Environ Microbiol 64, 795-799.

Melen, I., Lindahl, L., Andreasson, L. \& Rundcrantz, H. (1986). Chronic maxillary sinusitis. Definition, diagnosis and relation to dental infections and nasal polyposis. Acta Otolaryngol 101, 320-327.

Offenbacher, S., Jared, H. L., O'Reilly, P. G., Wells, S. R., Salvi, G. E., Lawrence, H. P., Socransky, S. S. \& Beck, J. D. (1998). Potential pathogenic mechanisms of periodontitis associated pregnancy complications. Ann Periodontol 3, 233-250.

Paster, B. J., Boches, S. K., Galvin, J. L., Ericson, R. E., Lau, C. N., Levanos, V. A., Sahasrabudhe, A. \& Dewhirst, F. E. (2001). Bacterial diversity in human subgingival plaque. J Bacteriol 183, 3770-3783.

Rajasuo, A., Jousimies-Somer, H., Savolainen, S., Leppänen, J., Murtomaa, H. \& Meurman, J. H. (1996). Bacteriologic findings in tonsillitis and pericoronitis. Clin Infect Dis 23, 51-60.

Rantakokko-Jalava, K., Nikkari, S., Jalava, J. \& 8 other authors (2000). Direct amplification of rRNA genes in diagnosis of bacterial infections. J Clin Microbiol 38, 32-39.
Scannapieco, F. A. (1999). Role of oral bacteria in respiratory infection. J Periodontol 70, 793-802.

Scannapieco, F. A., Stewart, E. M. \& Mylotte, J. M. (1992). Colonization of dental plaque by respiratory pathogens in medical intensive care patients. Crit Care Med 20, 740-745.

Stackebrandt, E. \& Goebel, B. M. (1994). Taxonomic note: a place for DNA-DNA reassociation and $16 \mathrm{~S}$ rRNA sequence analysis in the present species definition in bacteriology. Int J Syst Bacteriol 44, 846-849.

Suau, A., Bonnet, R., Sutren, M., Godon, J. J., Gibson, G. R., Collins, M. D. \& Dore, J. (1999). Direct analysis of genes encoding $16 S$ rRNA from complex communities reveals many novel molecular species within the human gut. Appl Environ Microbiol 65, 4799-4807.

van der Heijden, I. M., Wilbrink, B., Vije, A. E., Schouls, L. M., Breedveld, F. C. \& Tak, P. P. (1999). Detection of bacterial DNA in serial synovial samples obtained during antibiotic treatment from patients with septic arthritis. Arthritis Rheum 42, 2198-2203.

Wilson, K. H. \& Blitchington, R. B. (1996). Human colonic biota studied by ribosomal DNA sequence analysis. Appl Environ Microbiol 62, 22732278.

Wilson, M. J., Weightman, A. J. \& Wade, W. G. (1997). Applications of molecular ecology in the characterization of uncultured microorganisms associated with human disease. Rev Med Microbiol 8, 91-101.

Wilson, V. L., Tatford, B. C., Yin, X., Rajki, S. C., Walsh, M. M. \& LaRock, P. (1999). Species-specific detection of hydrocarbon-utilizing bacteria. J Microbiol Methods 39, 59-78. 